\title{
Neuro-protection in open arch surgery
}

\section{Yutaka Okita}

Division of Cardiovascular Surgery, Department of Surgery, Kobe University Graduate School of Medicine, Kobe, Japan

Correspondence to: Yutaka Okita, MD. Professor, Division of Cardiovascular Surgery, Department of Surgery, Kobe University Graduate School of Medicine, 7-5-2 Kusunoki-cho, Chuo-ku, Kobe 650-0017, Japan. Email: yokita@med.kobe-u.ac.jp.

\begin{abstract}
Although antegrade cerebral perfusion (ACP) is the predominant method of protecting the brain in patients undergoing total arch replacement, both deep hypothermic circulatory arrest and ACP provide excellent and comparable clinical outcomes with regard to mortality, stroke, and temporary neurological deficit rates.
\end{abstract}

Keywords: Aortic arch; arch replacement; brain protection; antegrade cerebral perfusion (ACP); deep hypothermia; retrograde cerebral perfusion (RCP)

Submitted Jan 18, 2018. Accepted for publication Apr 02, 2018.

doi: 10.21037/acs.2018.04.01

View this article at: http://dx.doi.org/10.21037/acs.2018.04.01

\section{Introduction}

As the number of elderly individuals in society increases, so too does the incidence of diseases involving the thoracic aorta. Consequently, while the number of open and endovascular procedures for the treatment of aortic arch lesions has increased, the outcomes of these interventions have also improved (1). Nonetheless, there is still room for improvement of outcomes in the strategies used for treatment of aortic arch lesions.

The most important aspects of aortic arch surgery are brain protection and secure anastomosis; however, one of the major causes of the newly developed postoperative stroke is cerebral embolism, which arises from atherosclerosis or thrombi at sites of aortic clamping, vascular anastomosis, and aortic or cerebral perfusion cannulation. Meticulous identification of preexisting atheroma in the aorta using preoperative computed tomography (CT), echogram, or intraoperative direct echogram, can provide important information about site selection for cannulation and clamping. In an experimental study, Fukuda et al. (2), using glass models of both healthy and aneurysmal aortic arches, have confirmed that directing the tip of the Dispersion cannula toward the aortic root generates slower and less turbulent flow in the transverse arch. Grooters et al. (3) have described the advantages of arterial perfusion toward the aortic valve and state that manipulation of the atheromatous aorta should be avoided to prevent atheroembolisms.
Although antegrade perfusion from the ascending aorta is preferred, occasionally, an atheromatous aorta precludes cannulation of the ascending aorta and peripheral arterial cannulation from the axillary artery or femoral artery is needed (2). However, axillary arterial cannulation can lead to atheroemboli from an atheromatous lesion at the orifice of the brachiocephalic artery (4), and retrograde embolization by debris from femoral artery cannulation is a well-recognized phenomenon.

Previous studies have reported an association between the severity of atheroma in aortic arch branches and the incidence of postoperative embolic stroke; recent reports indicate that the majority of permanent neurologic injuries are due to strokes resulting from embolic phenomena and that they were not directly related to the method of brain protection used (5). Amarenco and associates (6) have used data obtained from autopsies to show that the prevalence of ulcerated plaques in the aortic arch was $28 \%$ in 183 patients with cerebral infarcts and that it was $20 \%$ in 56 patients with brain hemorrhage. Blauth and associates (7) have demonstrated a direct correlation between age, severe atherosclerosis of the ascending aorta and atheroemboli. These results imply that accurate assessment of atheroma is essential for reducing the incidence of embolic stroke and that arterial cannulation sites should be chosen based on findings from preoperative computed tomography, MRI, carotid ultrasonography and intraoperative epiaortic 
scanning.

Wareing et al. (8) have reported modifications in their technique for cardiac procedures based on intraoperative echography findings; these include changing the site of aortic cannulation, aortic clamping, attachment of the vein grafts and cannulation for the infusion of cardioplegia, and have even performed hypothermic circulatory arrest (HCA) without aortic clamping. Our group has previously identified the degrees of severity of aortic arch atheroma as another risk factor for adverse neurological outcomes (9) and reported that presence of a shaggy atheromatous aorta was a significant risk factor for postoperative transient neurological dysfunction. The ideal method(s) of protecting the brain during aortic arch surgery have been pursued by DeBakey and others (10) before the era of cardiopulmonary bypass (CPB). They started using the extra-anatomical bypass to isolate circulation to the brain. Antegrade cerebral perfusion (ACP) under normothermia theoretically provides the best brain protection; however, it was associated with unsatisfactory clinical outcomes during the 1960's-1970's. As reported by Griepp et al. (11), deep hypothermic circulatory arrest (DHCA) does not require additional cannulas or clamps on the aortic arch branches, which might otherwise cause arterial damage or embolic stroke, or additional extracorporeal circuits such as those used in ACP. However, DHCA has the drawback of a limited safe duration. Svensson et al. (12), in a study of 656 patients undergoing aortic surgery using DHCA concluded that the occurrence of stroke increased after 40 minutes of circulatory arrest (CA) and that mortality rate increased markedly after 65 minutes of CA.

Ueda et al. (13) were the first to report that retrograde cerebral perfusion (RCP) provides a new approach to augment cerebral protection during CA. Similarly, in our experience (14), we have found that RCP is clearly effective in maintaining cerebral hypothermia, providing continuous cooling of the entire head, preventing air from reaching the terminal vessels of the brain and washing out some of the metabolites, thereby delaying the onset of acidosis in the ischemic brain. Coselli et al. (15), using data from a series of 479 patients, have reported that patients who had RCP during DHCA had lower mortality and stroke rates compared to those who did not undergo DHCA with RCP. Safi et al. (16) have demonstrated that the use of RCP had a protective effect against stroke compared to no RCP. Bavaria et al. (17) have reported that RCP might help extend the safe HCA period and improve morbidity and mortality, especially when HCA duration is longer than 60 minutes. However, the higher prevalence of transient neurological deficit (TND) indicates the need for caution against liberal use of RCP. Hagl et al. (18) have reported that the incidence of TND increased if the duration of RCP exceeded 25 minutes and that longer ACP duration also increased TND incidence. After the report by Spielvogel et al. (19), the arch-first technique using a branched arch graft became a standard procedure when RCP was applied during total arch replacement.

On the other hand, Frist et al. (20) have revived the concept of ACP and, in 1986, have reported 90\% survival after arch replacement using unilateral ACP with reduced cerebral blood flow under moderate hypothermia. Concurrently, Guilmet et al. (21) described the "cerebroplegia" method as cold ACP. Kazui et al. (22) have demonstrated ACP using a four-branched graft technique and report excellent surgical results with no neurological sequelae and three early deaths in 30 patients with acute aortic dissection. The most important advantage of ACP is that it provides the luxury of time, allowing for delicate repair of complicated arch aneurysms. However, there have been several criticisms against ACP, including longer duration for arch repair, cannulation-related embolism, and uneven distribution of intracranial blood flow. Nevertheless, the general consensus is that ACP can provide better and more uniform brain protection than DHCA for a longer duration. Di Eusanio et al. (23) have demonstrated that ACP of $>90 \mathrm{~min}$ is not associated with greater risk of mortality or negative neurological outcome. However, recent reports from our group $(9,24)$ have demonstrated that risk factors for postoperative stroke were the severity of the leukoaraiosis of the brain white matter and the presence of a "shaggy" aorta, while risk factors for TND were "shaggy" aorta, leukoaraiosis, carotid artery lesion and duration of CPB. These results imply that postoperative stroke is primarily dependent on both patient and pathology and that it is only marginally affected by cerebral protection technique used.

There have been a few randomized comparative studies but many retrospective studies on DHCA and ACP. We (25) have evaluated data from 60 consecutive total arch replacements allocated randomly to DHCA or ACP and concluded that both DHCA and ACP resulted in acceptable levels of mortality and morbidity, but that the prevalence of transient brain dysfunction was significantly higher with DHCA. Hagl et al. (18) have also retrospectively analyzed 
outcomes among 717 survivors of ascending and aortic arch surgery and show that the method of brain protection did not influence the incidence of stroke; however, ACP did result in a significant reduction in the incidence of TND. Svensson et al. (26) have analyzed postoperative neurocognitive function and serum S100 proteins in a prospective randomized study and report essentially no differences in outcomes among the ACP, the DHCA, and the DHCA/RCP groups. We have previously reported that patients undergoing RCP have a higher incidence of transient neurological dysfunction when starting with RCP for total arch replacement.

A recent meta-analysis of 5,060 patients from 15 studies by $\mathrm{Hu}$ et al. (27) has revealed that the incidence of postoperative stroke and TND were similar between ACP and RCP. Another meta-analysis by Tian et al. (28) has shown that stroke rates were significantly lower in patients undergoing selective antegrade cerebral perfusion (SACP) compared to patients who underwent DHCA. We have collected data from 8,169 patients who had undergone elective surgery of the total aortic arch from 2009 to 2012 from the Japanese Adult Cardiovascular Database to compare clinical outcomes between patients provided ACP and RCP (29). Mean age at surgery for the two groups was $70.5 \pm 10.1$ and $68.3 \pm 11.6$ years, respectively, and $51 \%$ were aged over 70 in both groups. In this patient cohort, $86.0 \%$ of all patients were provided ACP and $14.1 \%$ were provided $\mathrm{DHCA} \pm \mathrm{RCP}$. Lowest rectal temperature was below $25^{\circ} \mathrm{C}$ in $75.8 \%$ of patients with DHCA \pm RCP but was above $25{ }^{\circ} \mathrm{C}$ in $43.9 \%$ of the patients in the ACP group. A propensity-matched analysis of 1,141 patients showed that there was essentially no difference in postoperative survival or neurological outcome, except for prolonged ventilation time and ICU stay in the RCP group. Except for a few studies, in the majority of patients, ACP was used for protecting the brain during surgery, with early mortality ranging from $4.7 \%$ to $11.2 \%$ and permanent neurological deficits being observed in 1.3-6\% of all patients (30).

The amount of brain perfusion and pressure has been extensively investigated in animal experiments. However, controversies remain regarding unilateral brain perfusion, bilateral perfusion, or triple perfusion, because the patient groups in most clinical studies were a mix of hemiarch and total arch replacement. We have always have used three cannulae, which are inserted from inside the arch without snaring. Urbanski et al. (31) have used only one cannula to perfuse the entire brain and report low incidence of postoperative stroke. Many surgeons only choose to perfuse the brachiocephalic and left common carotid arteries, and not the left subclavian artery $(32,33)$. However, the presence of an incomplete Circle of Willis in the brain has been reported in $20 \%$ to $30 \%$ of the normal population (34) and sometimes the vertebral arteries can be hypoplastic or stenotic, especially in elderly patients. Further, the left subclavian artery is often a supplier of the collateral vessels to the spinal cord. A meta-analysis of ACP by Angeloni et al. (35) has demonstrated superiority of bilateral brain perfusion as the brain remained perfused for a longer duration compared to unilateral perfusion. Bilateral cerebral perfusion also seems to be a physiological method to perfuse the brain.

With respect to the lowest body temperature that can be reached during ACP, recent trends to avoid deep hypothermia have prevailed (36). The deep hypothermia tends to be associated with coagulopathy or lung injury; however, mild hypothermia does not protect the brain, the spinal cord, or the viscera, especially when unilateral ACP is applied. A comparison of body temperatures should also specify the site of measurement, such as tympanic, nasopharyngeal, esophageal, brain, rectal, or urethral (37). The optimal temperature during antegrade selective cerebral perfusion (SCP) has been reported to be between 20 and $28{ }^{\circ} \mathrm{C}(38,39)$. Kamiya et al. (40) have reported that body temperature during HCA can be safely increased to $28{ }^{\circ} \mathrm{C}$ with a high SCP flow rate and that this did not increase the incidence of adverse neurological events. In our practice, we set the tympanic temperature between 20 and $23{ }^{\circ} \mathrm{C}$, which results in optimal CA and SCP time $(42.4 \pm 27.8$ and $97.3 \pm 31.4 \mathrm{~min}$, respectively). In addition, function of the spinal cord and visceral organs should be carefully monitored during CA of the lower body, irrespective of whether it is performed under moderate hypothermia or normothermia.

Regarding rectal temperature, we aim to maintain it below $30{ }^{\circ} \mathrm{C}$ just prior to $\mathrm{CA}$ because our experience in one patient whose rectal temperature before CA was greater than $30{ }^{\circ} \mathrm{C}$ suffered necrosis of the entire colon, presumably because of the presence of calcified stenosis of the mesenteric artery with poor visceral circulation. To minimize $\mathrm{CPB}$ time, we also start re-warming as soon as the distal anastomosis is completed, with concurrent antegrade distal reperfusion to the lower body through a prosthetic graft branch. We then move to complete the proximal anastomosis, and usually terminate $\mathrm{CPB}$ immediately after arch vessel anastomosis. Monitoring brain oxygenation 
during rewarming is particularly important and we increase SCP flow from 10 to $15 \mathrm{~mL} / \mathrm{min} / \mathrm{m}^{2}$ to maintain preoperative values of near-infrared spectroscopy (NIRS) $(9,41)$; however, total flow is always maintained below $1,000 \mathrm{~mL} / \mathrm{min}$ to avoid brain edema.

The effects of rewarming on cerebral metabolism after HAC have not been adequately described in literature. In our study, rewarming speed affected the severity of TND among patients who had postoperative TND. Specifically, regional oxygen saturation $\left(\mathrm{SO}_{2}\right)$ was significantly lower during early rewarming (between the time points of 30 to 60 minutes after the initiation of SCP) in the patients with postoperative TND (42). A prospective randomized study by Cook and associates (43) showed a delay in normalization of cerebral metabolic rate during rewarming after moderate hypothermic $\mathrm{CPB}$, compared to the rapid recovery of cerebral blood flow, indicating a correlation between cerebral desaturation during early rewarming phase and cerebral damage.

Leukoaraiosis is patchy, punctuate, or confluent hyperintensity of white matter and deep gray nuclei in T2weighted images. This white matter hyperintensity reflects chronic ischemic damage to myelin and the axon (44). Several studies have demonstrated that there is a significant relationship between increased stroke risk and leukoaraiosis and we have (24) previously demonstrated that patients with severe leukoaraiosis were likely to develop temporary neurologic dysfunction and watershed stroke. We also found a significant correlation between leukoaraiosis and watershed infarcts.

Our current approach involves: (I) meticulous selection of arterial cannulation site and type of arterial cannula; (II) antegrade SCP for cerebral protection; (III) whole body moderate hypothermia with lower tympanic temperatures between 20 and $23{ }^{\circ} \mathrm{C}$ and rectal temperatures below $30^{\circ} \mathrm{C}$; (IV) early rewarming after distal anastomosis with antegrade SCP flow adjustment while monitoring brain oxygenation by NIRS; (V) maintenance of strict fluid balance below $1,000 \mathrm{~mL}$ using the extracorporeal ultrafiltration method (ECUM) during CPB with the expectation of greater and rapid pulmonary functional recovery. The table shows a recently reported series of a large cohort study on aortic arch replacement $(23,45-50)$ (Table 1).

\section{Conclusions}

We have reviewed the recent progress in open surgery for aortic arch aneurysms, which shows continuing improvement in surgical results over the last two decades. However, the number of patients has steadily increased as the population ages. Although recent advances in surgical skill, extracorporeal circulation equipment and accurate knowledge of the brain and visceral circulation have contributed to a reduction in postoperative stroke and mortality, subsequent refinement of these modalities is required for further improvement of these outcomes. Although ACP is the predominant method of protecting the brain in patients undergoing total arch replacement, this perspective indicates that both DHCA and ACP provide excellent and comparable clinical outcomes with regard to mortality, stroke and TND rates. Leukoaraiosis is a significant independent predictor of neurologic outcome in patients who undergo total arch replacement. However, the high prevalence of transient neurologic dysfunction necessitates further research to refine the protective methods used to prevent subtle brain injury. 


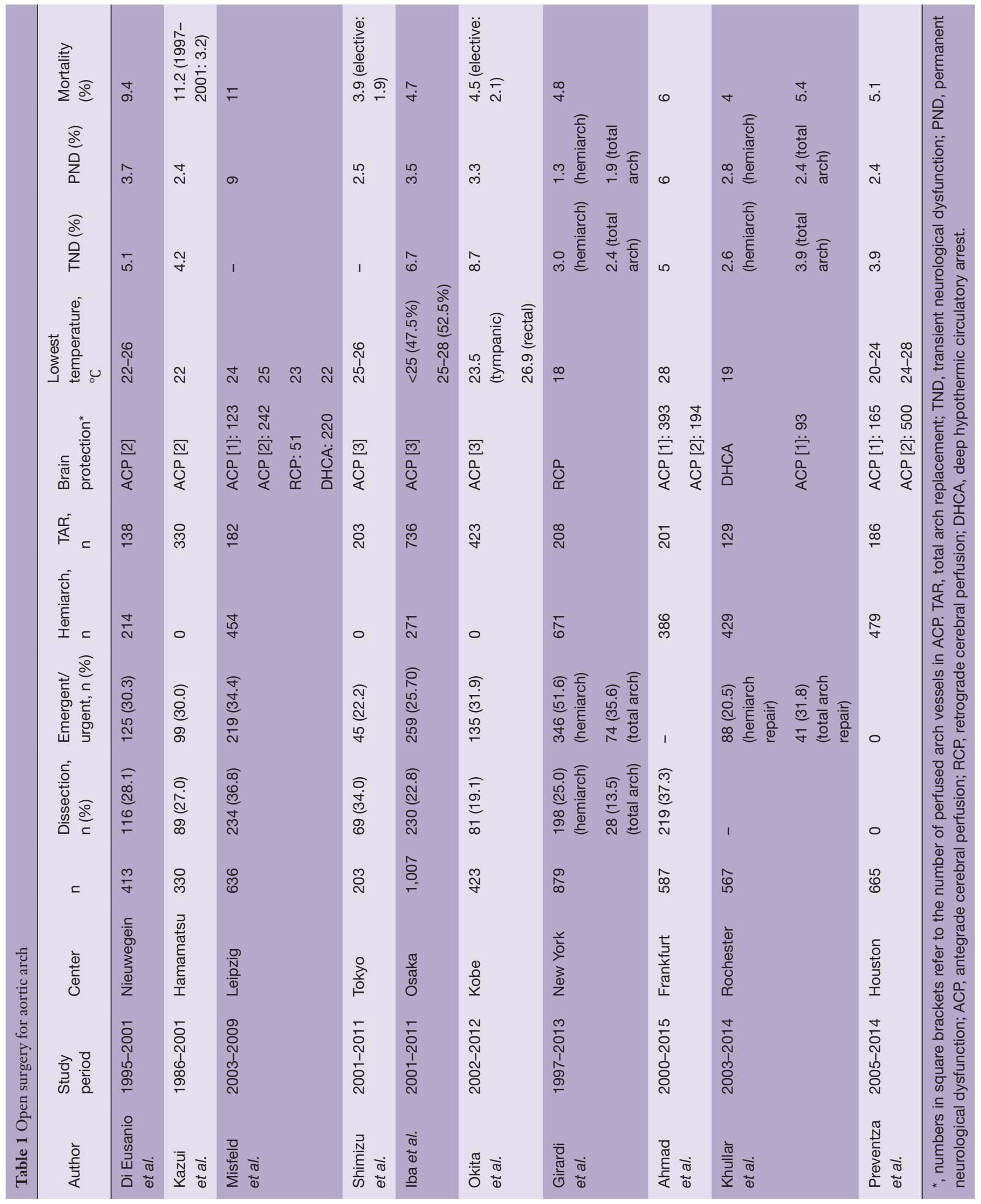




\section{Acknowledgements}

None.

\section{Footnote}

Conflicts of Interest: The author has no conflicts of interest to declare.

\section{References}

1. Committee for Scientific Affairs, The Japanese Association for Thoracic Surgery, Masuda M, et al. Thoracic and cardiovascular surgery in Japan during 2014 : Annual report by The Japanese Association for Thoracic Surgery. Gen Thorac Cardiovasc Surg 2016;64:665-97.

2. Fukuda I, Fujimori S, Daitoku K, et al. Flow velocity and turbulence in the transverse aorta of a proximally directed aortic cannula: hydrodynamic study in a transparent model. Ann Thorac Surg 2009;87:1866-71.

3. Grooters RK, Thieman KC, Schneider RF, et al. Assessment of perfusion toward the aortic valve using the new dispersion aortic cannula during coronary artery bypass surgery. Tex Heart Inst J 2000;27:361-5.

4. Sabik JF, Lytle BW, McCarthy PM, et al. Axillary artery: an alternative site of arterial cannulation for patients with extensive aortic and peripheral vascular disease. J Thorac Cardiovasc Surg 1995;109:885-90; discussion 890-1.

5. Okita Y, Ando M, Minatoya K, et al. Predictive factors for mortality and cerebral complications in arteriosclerotic aneurysm of the aortic arch. Ann Thorac Surg 1999;67:72-8.

6. Amarenco P, Duyckaerts C, Tzourio C, et al. The prevalence of ulcerated plaques in the aortic arch in patients with stroke. N Engl J Med 1992;326:221-5.

7. Blauth CI, Cosgrove DM, Webb BW, et al. Atheroembolism from the ascending aorta. An emerging problem in cardiac surgery. J Thorac Cardiovasc Surg 1992;103:1104-11; discussion 1111-2.

8. Wareing TH, Davila-Roman VG, Barzilai B, et al. Management of the severely atherosclerotic ascending aorta during cardiac operations. A strategy for detection and treatment. J Thorac Cardiovasc Surg 1992;103:453-62.

9. Okada K, Omura A, Kano H, et al. Recent advancements of total aortic arch replacement. J Thorac Cardiovasc Surg 2012;144:139-45.

10. Debakey ME, Henly WS, Cooley DA, et al. Aneurysms of the aortic arch: factors influencing operative risk. Surg
Clin North Am 1962;42:1543-54.

11. Griepp RB, Stinson EB, Hollingsworth JF, et al. Prosthetic replacement of the aortic arch. J Thorac Cardiovasc Surg 1975;70:1051-63.

12. Svensson LG, Crawford ES, Hess KR, et al. Deep hypothermia with circulatory arrest. Determinants of stroke and early mortality in 656 patients. J Thorac Cardiovasc Surg 1993;106:19-28; discussion 28-31.

13. Ueda Y, Miki S, Kusuhara K, et al. Surgical treatment of aneurysm or dissection involving the ascending aorta and aortic arch, utilizing circulatory arrest and retrograde cerebral perfusion. J Cardiovasc Surg (Torino) 1990;31:553-8.

14. Okita Y, Takamoto S, Ando M, et al. Mortality and cerebral outcome in patients who underwent aortic arch operations using deep hypothermic circulatory arrest with retrograde cerebral perfusion: no relation of early death, stroke, and delirium to the duration of circulatory arrest. J Thorac Cardiovasc Surg 1998;115:129-38.

15. Coselli JS, LeMaire SA. Experience with retrograde cerebral perfusion during proximal aortic surgery in 290 patients. J Card Surg 1997;12:322-5.

16. Safi HJ, Brien HW, Winter JN, et al. Brain protection via cerebral retrograde perfusion during aortic arch aneurysm repair. Ann Thorac Surg 1993;56:270-6.

17. Bavaria JE, Pochettino A. Retrograde cerebral perfusion (RCP) in aortic arch surgery: efficacy and possible mechanisms of brain protection. Semin Thorac Cardiovasc Surg 1997;9:222-32.

18. Hagl C, Ergin MA, Galla JD, et al. Neurologic outcome after ascending aorta-aortic arch operations: effect of brain protection technique in high-risk patients. J Thorac Cardiovasc Surg 2001;121:1107-21.

19. Spielvogel D, Halstead JC, Meier M, et al. Aortic arch replacement using a trifurcated graft: simple, versatile, and safe. Ann Thorac Surg 2005;80:90-5; discussion 95.

20. Frist WH, Baldwin JC, Starnes VA, et al. A reconsideration of cerebral perfusion in aortic arch replacement. Ann Thorac Surg 1986;42:273-81.

21. Guilmet D, Diaz F, Roux PM, et al. Aneurysm of the aortic arch. Surgical therapy. 60 cases. Presse Med 1986;15:2191-5.

22. Kazui T, Kimura N, Yamada O, et al. Total arch graft replacement in patients with acute type A aortic dissection. Ann Thorac Surg 1994;58:1462-8.

23. Di Eusanio M, Berretta P, Cefarelli M, et al. Longterm outcomes after aortic arch surgery: results of a study involving 623 patients. Eur J Cardiothorac Surg 
2015;48:483-90.

24. Morimoto N, Okada K, Uotani K, et al. Leukoaraiosis and hippocampal atrophy predict neurologic outcome in patients who undergo total aortic arch replacement. Ann Thorac Surg 2009;88:476-81.

25. Okita Y, Minatoya K, Tagusari O, et al. Prospective comparative study of brain protection in total aortic arch replacement: deep hypothermic circulatory arrest with retrograde cerebral perfusion or selective antegrade cerebral perfusion. Ann Thorac Surg 2001;72:72-9.

26. Svensson LG, Blackstone EH, Apperson-Hansen C, et al. Implications from neurologic assessment of brain protection for total arch replacement from a randomized trial. J Thorac Cardiovasc Surg 2015;150:1140-7.e11.

27. Hu Z, Wang Z, Ren Z, et al. Similar cerebral protective effectiveness of antegrade and retrograde cerebral perfusion combined with deep hypothermia circulatory arrest in aortic arch surgery: a meta-analysis and systematic review of 5060 patients. J Thorac Cardiovasc Surg 2014;148:544-60.

28. Tian DH, Wan B, Bannon PG, et al. A meta-analysis of deep hypothermic circulatory arrest alone versus with adjunctive selective antegrade cerebral perfusion. Ann Cardiothorac Surg 2013;2:261-70.

29. Okita Y, Miyata H, Motomura N, et al. A study of brain protection during total arch replacement comparing antegrade cerebral perfusion versus hypothermic circulatory arrest, with or without retrograde cerebral perfusion: analysis based on the Japan Adult Cardiovascular Surgery Database. J Thorac Cardiovasc Surg 2015;149:S65-73.

30. De Paulis R, Czerny M, Weltert L, et al. Current trends in cannulation and neuroprotection during surgery of the aortic arch in Europe. Eur J Cardiothorac Surg 2015;47:917-23.

31. Urbanski PP, Lenos A, Kolowca M, et al. Near-infrared spectroscopy for neuromonitoring of unilateral cerebral perfusion. Eur J Cardiothorac Surg 2013;43:1140-4.

32. Kazui T, Kimura N, Komatsu S. Surgical treatment of aortic arch aneurysms using selective cerebral perfusion. Experience with 100 patients. Eur J Cardiothorac Surg 1995;9:491-5.

33. Bachet J, Goudot B, Dreyfus GD, et al. Surgery for acute type A aortic dissection: the Hopital Foch experience (1977-1998). Ann Thorac Surg 1999;67:2006-9; discussion 2014-9.

34. Papantchev V, Stoinova V, Aleksandrov A, et al. The role of Willis circle variations during unilateral selective cerebral perfusion: a study of 500 circles. Eur J Cardiothorac Surg 2013;44:743-53.

35. Angeloni E, Benedetto U, Takkenberg JJ, et al. Unilateral versus bilateral antegrade cerebral protection during circulatory arrest in aortic surgery: a meta-analysis of 5100 patients. J Thorac Cardiovasc Surg 2014;147:60-7.

36. Okita Y, Okada K, Omura A, et al. Total arch replacement using antegrade cerebral perfusion. J Thorac Cardiovasc Surg 2013;145:S63-71.

37. Yan TD, Bannon PG, Bavaria J, et al. Consensus on hypothermia in aortic arch surgery. Ann Cardiothorac Surg 2013;2:163-8.

38. Minatoya K, Ogino H, Matsuda H, et al. Evolving selective cerebral perfusion for aortic arch replacement: high flow rate with moderate hypothermic circulatory arrest. Ann Thorac Surg 2008;86:1827-31.

39. Preventza O, Coselli JS, Garcia A, et al. Moderate hypothermia at warmer temperatures is safe in elective proximal and total arch surgery: Results in 665 patients. $J$ Thorac Cardiovasc Surg 2017;153:1011-8.

40. Kamiya H, Hagl C, Kropivnitskaya I, et al. The safety of moderate hypothermic lower body circulatory arrest with selective cerebral perfusion: a propensity score analysis. J Thorac Cardiovasc Surg 2007;133:501-9.

41. Okita Y, Okada K, Omura A, et al. Surgical techniques of total arch replacement using selective antegrade cerebral perfusion. Ann Cardiothorac Surg 2013;2:222-8.

42. Shirasaka T, Okada K, Kano H, et al. New indicator of postoperative delayed awakening after total aortic arch replacement. Eur J Cardiothorac Surg 2015;47:101-5.

43. Cook RC, Gao M, Macnab AJ, et al. Aortic arch reconstruction: safety of moderate hypothermia and antegrade cerebral perfusion during systemic circulatory arrest. J Card Surg 2006;21:158-64.

44. Lin R, Svensson L, Gupta R, et al. Chronic ischemic cerebral white matter disease is a risk factor for nonfocal neurologic injury after total aortic arch replacement. J Thorac Cardiovasc Surg 2007;133:1059-65.

45. Iba Y, Minatoya K, Matsuda H, et al. Contemporary open aortic arch repair with selective cerebral perfusion in the era of endovascular aortic repair. J Thorac Cardiovasc Surg 2013;145:S72-7.

46. Kazui T, Yamashita K, Washiyama N, et al. Aortic arch replacement using selective cerebral perfusion. Ann Thorac Surg 2007;83:S796-8; discussion S824-31.

47. Misfeld M, Leontyev S, Borger MA, et al. What is the best strategy for brain protection in patients undergoing aortic arch surgery? A single center experience of 636 patients. 
Ann Thorac Surg 2012;93:1502-8.

48. Shimizu H, Matayoshi T, Morita M, et al. Total arch replacement under flow monitoring during selective cerebral perfusion using a single pump. Ann Thorac Surg 2013;95:29-34.

49. Girardi LN, Shavladze N, Sedrakyan A, et al. Safety and efficacy of retrograde cerebral perfusion as an adjunct for cerebral protection during surgery on the aortic arch. J Thorac Cardiovasc Surg 2014;148:2927-33.

50. Khullar V, Schaff HV, Dearani JA, et al. Open Surgical Repair Remains the Gold Standard for Treating Aortic Arch Pathology. Ann Thorac Surg 2017;103:1413-20.

Cite this article as: Okita Y. Neuro-protection in open arch surgery. Ann Cardiothorac Surg 2018;7(3):389-396. doi: 10.21037/acs.2018.04.01 